\title{
MANEJO PRÉ-ABATE DE BOVINOS DE CORTE NO PANTANAL, BRASIL
}

\author{
PRE-SLAUGHTER HANDLING OF BEEF CATTLE IN THE PANTANAL, BRAZIL
}

\author{
Andrade, E.N. ${ }^{1 *}$, R.A.M.S. Silva² e R.O. Roça ${ }^{3}$
}

\begin{abstract}
${ }^{1}$ Faculdade de Medicina Veterinária (FMVZ). Universidade Estadual Paulista (UNESP). Rua Dr. José Barbosa de Barros, 835. Jardim Paraíso. CEP 18609-085. Botucatu, SP. Brasil. *ernani@fmvz.unesp.br ${ }^{2}$ Embrapa Pantanal. Cx. Postal 109. 79320-900 Corumbá, MS. Brasil. roberto.aguilar1@terra.com.br ${ }^{3}$ Departamento de Gestão e Tecnologia Agroindustrial (DGTA). Faculdade de Ciências Agronômicas. UNESP. Cx. Postal 237. 18603-970 Botucatu, SP. Brasil. robertoroca@fca.unesp.br
\end{abstract}

\section{PalaVRas ChaVES ADICIONAIS}

Transporte fluvial. Lesões em carcaças. Transporte rodoviário. Tempo de transporte.

\section{RESUMO}

Objetivou-se avaliar a influência do transporte fluvial e rodoviário na ocorrência de lesões em carcaças de bovinos abatidos no Pantanal Sul Mato-grossense. No estudo foi observado que do total de 209 carcaças avaliadas, $185(88,5 \%)$ tiveram uma ou mais lesões, totalizando 523 lesões que resultaram na remoção de $96,158 \mathrm{~kg}$ de carne, com média geral de $0,460 \mathrm{~kg}$ por animal ou 0,519 $\mathrm{kg}$ por animal considerando-se apenas os animais que tiveram lesões. Foi possível determinar a idade das lesões em carcaças, avaliando a coloração das mesmas. Concluiu-se que o meio de transporte influenciou a ocorrência de lesões. O uso da metodologia de avaliação da cor das lesões foi possível estimar, em qual momento do manejo ou meio de transporte ocorram mais lesões. A maioria das lesões ocorreram nas últimas 24 horas antes do abate. Medidas educativas devem ser implementadas para reduzir os problemas do manejo pré-abate.

\section{SUMMARY}

This study has the objective of evaluate the influence of fluvial and road transport on the occurrence of bruising in carcass of slaughtered beef cattle. In this study was observed that from 209 evaluated carcass, 185 (88.5\%) presented one or more lesions. In total of evaluated carcass occurred 523 lesions that resulted in $96.158 \mathrm{~kg}$ removal of bruises $(0.519 \mathrm{~kg}$ per animal). In this

Recibido: 21-6-07. Aceptado: 28-6-07.

\section{Additional KeYWORDS}

Fluvial transport. Bruises in carcasses. Road transport. Time of transport.

study was possible the determination of age of bruises by color evaluation. We concluded that of way of transport influenced the occurrence of bruises. The most bruises occurred in the last 24 hours of transport. Educational measures will be necessary to reduce the problems of pre-slaughter management.

\section{INTRODUÇÃO}

O manejo pré-abate deficiente reduz o bem estar animal. Atualmente, atenção tem sido dada sobre saúde e bem estar animal, pois alimentos de origem animal produzidos humanitariamente são um significante nicho de mercado de alimentos e constitui num dos requisitos de produção orgânica ou sustentável. O transporte dos bovinos, após estarem prontos para o abate, é uma importante etapa no processo da criação desses animais e da produção da carne. É vital que esse processo seja feito da maneira mais adequada, através da utilização dos métodos e técnicas mais indicadas.

O Pantanal é uma planície estacionalmente inundável, com aproximadamente $139558 \mathrm{~km}^{2}$ (Silva et al., 1995), onde fazendas de criação extensiva de bovinos ocupam a maior parte da área. A pecuária de corte na 
região do Pantanal encontra-se espalhada em todo Pantanal.

É freqüente a utilização de várias formas de transporte do gado no Pantanal ao longo do escoamento, variando com as condições locais e o estado do animal, entre outras. Nas propriedades mais distantes e de difícil acesso, predomina o transporte por comitiva até os centros de embarque fluvial ou rodoviário.

Este trabalho visa avaliar a influência do transporte fluvial e rodoviário na ocorrência de lesões em carcaças de bovinos abatidos no Pantanal Sul Mato-grossense, assim como localizar a freqüência de ocorrência das lesões nos principais cortes comerciais brasileiros e identificar e determinar a idade das lesões em função do tempo ocorrido.

\section{MATERIALE MÉTODOS}

Utilizaram-se como animais experimentais 209 bovinos, provenientes de 7 regiões localizadas em diferentes sub-regiões do Pantanal.

Os animais foram divididos em 9 tratamentos, de acordo com a distância da fazenda e transporte.

O transporte via rodoviário foi realizado da fazenda de origem dos animais até o frigorífico, os bovinos foram submetidos a idêntico manejo pré-abate: jejum e dieta hídrica de 12 horas. No transporte via fluvial, os animais primeiro eram levados a pé da fazenda de origem até o porto mais próximo, onde eram embarcados na lancha-curral e transportado até o porto da cidade de Ladário. Ficavam em média 1 dia no curral do porto em jejum com água a vontade, posteriormente eram transportados via rodoviária $(25 \mathrm{~km})$ até o frigorífico, os bovinos foram submetidos a idêntico manejo pré-abate: jejum e dieta hídrica de 12 horas.

Durante o abate, cada carcaça foi avaliada e numerada em ficha individual, onde anotava-se a ocorrência, conforme um formulário próprio. As carcaças que apresentaram lesões foram submetidas à
Tabela I. Determinação da idade das lesões conforme a escala colorimétrica. (Determining age of bruises according to colour scale).

\begin{tabular}{|c|c|}
\hline Tempo & Coloração/Aspecto \\
\hline Menos de 1 dia & Vermelho/azulado ou púrpura \\
\hline $1-2$ dias & Marrom para púrpura escuro \\
\hline $3-5$ dias & Verde para marrom \\
\hline $5-7$ dias & Amarelo* \\
\hline + de 1 semana & Amarelo-marrom* \\
\hline
\end{tabular}

*aspecto exudativo.

remoção dos tecidos afetados na operação de toalete, conforme procedimento próprio de cada frigorífico. As lesões removidas foram colhidas e separadas em sacos plásticos individualmente de acordo com o número da carcaça com lesão e o peso total foi anotado segundo ao tratamento de origem. Todas as lesões foram pesadas no laboratório da Empresa Brasileira de Pesquisa Agropecuária - Embrapa Pantanal.

A determinação da idade das lesões foi baseada na escala de cores das mesmas conforme tabela I. Durante o abate, cada carcaça foi inspecionada e numerada em ficha individual, onde registrava-se a cor da lesão. Foram feitas avaliações subjetivas visuais para validação de lesões de carcaça, baseando-se na escala colorimétrica. As identificações visuais das lesões foram realizadas, logo após as avaliações das carcaças.

$\mathrm{O}$ teste não paramétrico de KruskalWallis foi utilizado para comparações múltiplas entre médias de tratamento para as características: idade das lesões em função da sua coloração. Consideraram-se significativas às diferenças com $p<0,01$. $O$ Sistema de Analises Estatísticas e Genéticas, SAEG 9.0 (UFV, 1997) foi utilizado para analise dos dados.

\section{RESULTADOSEDISCUSSÃO}

Verificou-se que do total de 209 carcaças 
avaliadas, $185(88,5 \%)$ tiveram uma ou mais lesões, totalizando 523 lesões que resultaram na remoção de $96,158 \mathrm{~kg}$ de carne, com média geral de $0,460 \mathrm{~kg}$ por animal ou 0,519 $\mathrm{kg}$ por animal considerando-se apenas os animais que tiveram lesões. Segundo Gregory (1994), o manejo pré-abate inadequado compromete o bem-estar animal, causando desde contusões, fraturas, arranhões, exaustão metabólica, desidratação, estresse de temperatura, até morte. Todos podem ocorrer durante o transporte inadequado. Knowles (1999), afirma que o transporte rodoviário em condições desfavoráveis como aumento do jejum, desidratação, cansaço, espaço diminuído, pode provocar a morte ou conduzir a contusões, perda de peso e estresse dos animais. Para Warriss (1990) as lesões podem ocorrer em qualquer momento do comércio, no manejo na fazenda, transporte e até o momento imediatamente seguinte ao atordoamento antes da sangria.

As médias da idade das lesões avaliadas por meio da escala de cores, em função dos tratamentos são apresentadas na tabela II.

Tabela II. Médias da idade das lesões avaliadas pela escala de cores em função dos tratamentos. (Average age of bruises assessed by colour in function of treatment).

\begin{tabular}{lcc}
\hline Origem & $\begin{array}{c}\text { Médias dos } \\
\text { dados }\end{array}$ & $\begin{array}{c}\text { Total de } \\
\text { lesões }\end{array}$ \\
\hline Tratamento I & $1,00^{\mathrm{a}}$ & 21 \\
Tratamento II & $1,15^{\mathrm{a}}$ & 80 \\
Tratamento III & $1.06^{\mathrm{a}}$ & 15 \\
Tratamento IV & $1,27^{\mathrm{a}}$ & 33 \\
Tratamento V & $2,93^{\mathrm{b}}$ & 93 \\
Tratamento VI & $1,51^{\mathrm{b}}$ & 87 \\
Tratamento VII & $1,35^{\mathrm{a}}$ & 28 \\
Tratamento VIII & $1,71^{\mathrm{b}}$ & 146 \\
Tratamento IX & $3,05^{\mathrm{b}}$ & 20 \\
\hline
\end{tabular}

Letras diferentes indicam que os valores são estatisticamente diferentes entre si $(p<0,01)$ pelo teste Kruskal-Wallis.
Os animais provenientes dos tratamentos V, VI, VIII e IX apresentaram as maiores médias (tabela II). Este achado provavelmente esteja relacionado ao tempo de manejo e a serie sucessiva de manejo, a qual os animais foram submetidos ficando desta forma expostos a sofrir lesões. Os animais oriundos do tratamento $\mathrm{V}$ foram submetidos aos procedimentos de leilão, onde foram submetidos a inúmeros manejos até serem leiloados e em seguida transportados em caminhão até o frigorífico, tempo gasto do inicio dos procedimentos de manejo no leilão até 0 abate foi de 5 dias. Eldridge et al. (1984) concluíram que bovinos comercializados em leilões apresentaram maior quantidade de lesões, e mais severas que aqueles enviados diretamente para o matadouro. Tais relatos reforçam e justificam os resultados apresentados na tabela II.

Já os animais provenientes dos tratamentos VI, VIII e IX submetidos ao transporte fluvial, passaram por vários manejos, inclusive 2 embarques e desembarques, sendo que durante os dias de transporte fluvial os animais permaneceram desprovidos de alimento e água, desta forma, as maiores médias de lesões encontrada neste estudo possivelmente esteja relacionada ao aumento do tempo de transporte, jejum e número de interaçãos homem-animal durante o manejo pré-bate, sendo que o tempo consumido desde a fazenda de origem dos animais até o frigorífico foi mais de uma semana.

\section{CONCLUSÕES}

$\mathrm{O}$ meio de transporte influenciou a ocorrência de lesões. Com o uso da metodologia de avaliação da cor das lesões é possível estimar, em qual momento do manejo ou meio de transporte ocorrem lesões. A maioria das lesões ocorreram nas ultimas vinte e quatro horas antes do abate. Medidas educativas devem ser implementadas para reduzir os problemas do manejo pré-abate. 


\section{ANDRADE, SILVAEROÇA}

\section{BIBLIOGRAFIA}

Eldridge, G.A., J.L. Barnett, I.P. McCausland, H.W.C. Millar and W.J. Vowles. 1984. Bruising and method of marketing cattle. J. Austral. Soc. Anim. Prod., 15: 675.

Gregory, N.G. 1994. Pre-slaughter, handing, stunning and slaughter. Meat Sci., 36: 4656.

Knowles, T.G. 1999. A review of the road transport de cattle. Vet. Rec., 144: 197-201.

UFV. 1997. SAEG. Sistema de análise estatística e genéticas (Versão 7.0). Universidade Federal de Viçosa, UFV. Viçosa, MG.

Silva, J.S.V., M.M. Abdon e M.P. Silva. 1995. Delimitação do Pantanal brasileiro e suas subregiões. Em: Encontro sobre sensoriamento remoto aplicado a estudos no Pantanal. INEP. São José dos Campos. p. 9-10.

Warriss, P.D. 1990. The handling of cattle preslaughter and its effects on carcass and meat quality. Appl. Anim. Behav. Sci., 28: 171-186.

Archivos de zootecnia vol. 58, núm. 222, p. 304. 